\title{
A Lei de Responsabilidade na Gestão Fiscal: Combatendo Falhas de Governo à Brasileira
}

\author{
The law of fiscal management responsibility: \\ Combating government failures in the Brazilian way
}

CARLOS ANTONIO LUQUE*,+

VERA MARTINS DA SILVA**, ${ }^{++}$

RESUMO: O objetivo deste artigo é analisar os principais aspectos do novo regulamento, a chamada "Lei de Responsabilidade na Gestão Fiscal”, utilizando a estrutura do desequilíbrio orçamentário como uma falha do governo. Ressaltamos que o princípio da nova regulamentação é que, se o planejamento do governo for altamente detalhado e o déficit estiver sob controle, não observaremos inflação nem pressões de endividamento. Existem dois grandes problemas de controle: limites para despesas com salários de pessoal e o montante da dívida. O novo regulamento restringe a ação pública durante o último ano do mandato e trata da importância de divulgar informações sobre questões fiscais e a participação do público nas práticas orçamentárias. Apesar dos bons aspectos da regulamentação - especialmente no último ano dos gastos de um determinado governo, ainda há alguns problemas: a falta de discussão sobre o tamanho adequado e as funções do governo e o componente anticíclico da ação governamental que é desprezado pela lei.

PALAVRAS-CHAVE: Regulação; fracasso do governo; planejamento público; tamanho do governo; saldo orçamental.

ABSTRACT: The purpose of this article is analyzing the principal aspects of the new regulation, the so-called "Lei de Responsabilidade na Gestão Fiscal” using the framework of the budget imbalance as a government failure. We pointed out that the principle of the new regulation is that if the government planning is highly detailed and the deficit is under control, we will observe neither inflation nor debt pressures. There are two great issues of control: limits to expenditures with personnel's salaries and the amount of debt. The new

\footnotetext{
* Professor titular do Departamento de Economia da Universidade de São Paulo - USP, São Paulo/SP, Brasil,e-mail: cluque@usp.br.

+ Secretário-Adjunto da SEP/SP, São Paulo-SP, Brasil.

* Professora licenciada da Universidade da Fundação Escola de Comércio Alvares Penteado - UNIFECAP, São Paulo/SP, Brasil, e-mail: veramartins2702@gmail.com. Submetido: junho 2002; aceito: junho 2003.

++ Assessora da Sociedade Brasileira de Economia Política da SEP/SP, São Paulo-SP, Brasil..
} 
regulation restrains the public action during the last year of mandate and deals with the importance of spreading information on fiscal issues and the public participation on the budgetary practices. Despite the good aspects of the regulation - especially on the last year of a given government's expenditures, there are still some problems: the lack of discussion on the adequate size and functions of the government and the anti-cyclical component of the government action which is despised by the law.

KEYWORDS: Regulation; government failure; public planning; size of government; budget balance.

JEL Classification: H60; H61; H62; H63.

\section{INTRODUÇÃO}

A literatura sobre "falhas de governo" normalmente associa alguns problemas de ordem gerencial ao mau desempenho do setor governamental. Stiglitz (1988), por exemplo, cita quatro grandes razões para a existência de falhas sistemáticas do governo em atingir seus objetivos: 1 ) informação limitada, o que dificulta a tomada de decisão e a análise do impacto das ações públicas; 2) controle limitado sobre a resposta do setor privado à ação governamental; 3) baixo controle sobre a buro 4) limitações no processo político, tais como inconsistência nas escolhas públicas e captura dos políticos por grupos de interesse.

Podemos adicionar mais outra "falha de governo": a tendência à existência de uma situação de desequilíbrio orçamentário crônico, principalmente em países menos desenvolvidos, onde as demandas de despesas públicas excedem largamente as receitas factíveis.

O comportamento dos políticos, muitas vezes contraditório ao longo do tempo, e a persistência de desequilíbrios orçamentários acabam levando a uma redução da confiabilidade da ação pública. A introdução e efetiva implementação de regras para a conduta pública deve minimizar essas "falhas de governo", reduzindo a percepção de risco do governo por parte da sociedade e ampliando a confiança no governo, independentemente do grupo político que esteja no poder.

É no sentido de minimizar condutas indesejáveis dos dirigentes públicos e tentar ampliar a eficiência do processo orçamentário governamental equilibrado que um novo arcabouço institucional foi criado, com a aprovação da Lei Complemen$\operatorname{tar} \mathrm{n}^{\circ} 101$, de 4 de maio de 2000, conhecida como Lei de Responsabilidade na Gestão Fiscal (LRF), complementada pela Lei n ${ }^{\circ}$ 10.028, de 19 de outubro de 2000, que estabelece penas - que variam de multa até reclusão de até 4 anos - para os gestores que desobedecerem algumas das regras estabelecidas. A Lei Complemen$\operatorname{tar} \mathrm{n}^{\circ} 101$ regulamenta alguns artigos da Constituição de 1988, especialmente o artigo 163, que dispõe sobre finanças públicas, o artigo 165, sobre o sistema orçamentário do setor público e o artigo 169 relativo às despesas públicas com pessoal. 
Para disseminar a chamada prática de gestão fiscal responsável por todos os níveis de governo, portanto, abrangendo União, estados, municípios e seus órgãos indiretos, esse novo conjunto de regras possui cinco grandes objetivos: 1) o planejamento fiscal; 2) o disciplinamento do uso dos recursos públicos no último ano de mandato; 3) a definição de condições para o endividamento e gasto financeiro público; 4) a definição de limites de gastos com pessoal, incluindo previdência, por nível de governo e pelos diversos poderes; 5) a incorporação da transparência e participação popular na gestão fiscal. Para a efetiva implementação das novas regras, foram criadas também penalidades.

A LRF fixa os parâmetros para os cinco primeiros pontos e já apresenta algumas penalidades de caráter fiscal. As penalidades mais severas encontram-se na Lei $\mathrm{n}^{\circ} 10.028$ de 2000. Este artigo discutirá cada um destes tópicos no novo arcabouço institucional, destacando-se também uma avaliação crítica sob o enfoque macroeconômico.

\section{PLANEJAMENTO FISCAL}

O principal instrumento para a gestão fiscal responsável é a efetiva utilização do planejamento fiscal, realista e responsável. O sistema brasileiro de planejamento público, previsto pelo Artigo 165 da Constituição Federal, inclui: 1) o Plano Plurianual, que estabelece diretrizes, objetivos e metas para as despesas de capital e programas de duração continuada; 2) a lei de diretrizes orçamentárias, que orienta a elaboração do orçamento anual, adequando-o ao plurianual, assim como estabelece alterações na política tributária e na política das agências de fomento e 3) o orçamento anual, que estima as receitas e define as despesas para o ano seguinte.

A lógica dessas leis parte do princípio de que o Plano Plurianual procura nortear as ações do setor público pelo prazo de quatro anos, cabendo às Leis de Diretrizes Orçamentárias as estratégias para a elaboração do orçamento, completando-se com a própria elaboração do orçamento anual. A Constituição exige também no seu artigo 167 que nenhum investimento, cuja execução ultrapasse um exercício financeiro, poderá ser iniciado sem prévia inclusão no Plano Plurianual, ou sem lei autorizativa da inclusão.

No que diz respeito ao planejamento público dos três níveis de governo, o artigo da LRF que disporia sobre o Plano Plurianual foi vetado, por exigir que este fosse elaborado até 30 de abril do primeiro ano de governo, prazo considerado muito curto face à complexidade e abrangência do instrumento. ${ }^{1}$ Recaiu sobre a Lei de Diretrizes Orçamentárias (LDO) o papel de principal orientadora das ações públicas. O Art. 4 da LRF determina que a Lei de Diretrizes Orçamentárias - LDO,

\footnotetext{
${ }^{1} \mathrm{O}$ veto eliminou também o anexo de Política Fiscal, que estabelecia objetivos e metas dos planos plurianuais, cujo detalhamento ficou para o Anexo de Metas Fiscais da LDO.
} 
que fornece os parâmetros para a elaboração do orçamento do ano seguinte, incorpore o Anexo de Metas Fiscais, onde devem ser explicitadas, para o exercício a que se referem e para os dois seguintes:

- as receitas e despesas despesas, em valores correntes e constantes;

- resultados nominal e primário;

- montante da dívida pública;

- uma avaliação do cumprimento das metas do ano anterior;

- demonstrativo das metas anuais e metodologia de cálculo comparando com as fixadas nos três exercícios anteriores, destacando a compatibilidade entre as premissas adotadas e os objetivos da política econômica nacional;

- evolução do patrimônio líquido dos últimos três exercícios, destacando a origem e aplicação dos recursos obtidos com a alienação de ativos;

- avaliação da situação financeira e atuarial dos regimes de previdência e fundos de natureza atuarial;

- demonstrativo da renúncia e compensação de renúncia de receita;

- demonstrativo da margem de expansão das despesas de caráter continuado.

A LRF veio a consolidar, em conjunto com a própria Lei 4.320 de 1964, que todavia rege a legislação orçamentária, um enfoque mais rígido sobre as despesas de pessoal e os limites de endividamento para a obtenção do equilíbrio orçamentário. Devemos também observar que a imposição do Anexo de Metas Fiscais quando da elaboração da Lei de Diretrizes Orçamentárias antecipa a previsão de receitas e despesas para o ano seguinte e os dois períodos subseqüentes. A lógica dessa exigência reside no fato de que em determinadas situações o Executivo inicia ações, para as quais ele conta com recursos para um determinado ano, sem, contudo, efetuar nenhuma previsão de que tais ações podem implicar gastos futuros.

Observe-se que, embora todo o conjunto de regras, antigas como a Lei 4.320, ou novas como a Lei de Responsabilidade Fiscal, sugira o estabelecimento de metas orçamentárias superavitárias, não há na LRF uma obrigação legal para isso, de modo que pode-se dizer que uma administração poderá até estabelecer um resultado negativo em determinado período, se assim julgar conveniente.

A LDO deve conter, também, o Anexo de Riscos Fiscais, o qual deve ser explicitar os problemas capazes de afetar as contas públicas e as providências a serem tomadas caso estes se concretizem. ${ }^{2}$

\footnotetext{
${ }^{2}$ No caso da LDO do Estado de São Paulo para 2002, por exemplo, encontram-se indicados os problemas com indenizações ambientais bilionárias, questionadas na justiça. No caso do Município de São Paulo, a LDO para 2002 aponta problemas com dívidas diversas, e especialmente, o problemas dos precatórios judiciais.
} 
No caso específico da União, deverão ainda ser explicitados os objetivos das políticas monetária, creditícia e cambial e as metas de inflação para o exercício seguinte.

Observando-se os quesitos determinados pela lei no que tange à LDO, nota-se que a administração pública tende a se tornar muito mais detalhada, com um grau de sofisticação elevado que certamente trará benefícios do ponto de vista fiscal e administrativo. Permanece, contudo, a preocupação sobre a capacidade de adequação dos entes federativos e diversos poderes a esse novo instrumento legal, tendo-se em conta a abrangência nacional da lei e a diversidade administrativa e econômico-financeira dos segmentos atingidos por ela. É bem verdade que no caso dos municípios com população inferior a 50 mil habitantes, o Anexo das Metas fiscais e o Anexo dos Riscos Fiscais só entrarão em vigor a partir do quinto exercício seguinte ao da publicação da lei.

Ainda no processo orçamentário, a Lei Orçamentária anual deve seguir os parâmetros estipulados na LDO e a execução orçamentária deverá ser também mais detalhada: até trinta dias após a publicação do orçamento, o Poder Executivo deverá estabelecer a programação financeira e o cronograma mensal de desembolso. Se ao final de um bimestre as metas não puderem ser atingidas, os responsáveis deverão adequar os gastos nos trinta dias seguintes. ${ }^{3}$

Uma novidade da LRF é a exigência da instituição e efetiva arrecadação de todos os tributos de competência dos entes federados, sob pena destes não poderem mais receber transferências voluntárias de outros entes. ${ }^{4}$ Tal dispositivo é extremamente relevante para o equilíbrio fiscal do setor público uma vez que há inúmeras prefeituras e estados que, no passado, foram absolutamente omissos quanto à sua arrecadação própria, preferindo viver quase exclusivamente de transferências de níveis superiores de governo. Nesse sentido, os críticos da LC 101 têm razão quando afirmam que ela levará a um aumento da carga tributária global do sistema, pois é de se esperar um aumento do esforço fiscal por parte de estados e prefeituras. Ainda que ocorra esse ajuste tributário, não se deve esperar que o aumento da carga tributária seja generalizado ou que comprometa a competitividade dos produtos brasileiros no exterior, pois em geral os setores mais modernos e competitivos já são aqueles mais cobertos pela tributação. Deve-se esperar, isto sim, um aumento na arrecadação de tributos sobre a propriedade e serviços, no âmbito municipal e do Imposto sobre a Circulação de Bens e Serviços (ICMS), no nível dos estados, principalmente os do Norte e Nordeste. Por outro lado, o fato de a União não ter ainda instituído o imposto sobre grandes fortunas leva a crer que a LRF é um instrumento para incentivar o ajuste fiscal de estados e municípios e menos de si mesmo, principalmente no que diz respeito à receita tributária própria.

\footnotetext{
${ }^{3}$ LC 101, Art. 9.

${ }^{4}$ LC 101, Art. 11.
} 
Com relação à guerra fiscal, a LRF exige que a concessão ou ampliação de benefício tributário seja acompanhada de estimativa do impacto orçamentário - no exercício em que se iniciar e nos dois seguintes - e também de medidas de compensação, por elevação de alíquotas, base de cálculo ou criação de tributo ou contribuição. ${ }^{5}$ Note-se que a literatura internacional sobre federalismo fiscal caminha no sentido oposto ao preconizado pela LC 101, indicando que a competição fiscal entre entes federativos, no sentido de reduzir os custos fiscais e ampliar a oferta de serviços públicos à população é um modelo desejável e aponta a atração de empresas e famílias para as localidades mais bem sucedidas nessa questão.

No sentido de reforçar o princípio do equilíbrio, a LC 101 impõe que aumentos das despesas continuadas sejam compensados por aumentos permanentes da receita. ${ }^{6}$ Note-se que esta restrição ao uso da despesa pública não se aplica às despesas com serviço da dívida, o que gera uma crítica quanto à qualidade dos gastos públicos, na medida em que a lei daria maior liberdade aos gastos com juros do que com programas sociais. Em defesa da LRF pode-se dizer que ela estabelece que em caso de aumento de despesa continuada, por exemplo, a elevação do salário mínimo, que tem um impacto importante sobre as contas da previdência de caráter irreversível, o governo é obrigado a criar receita nova para equilibrar o aumento da despesa. Já no caso das despesas com juros, a idéia é que o ajuste possa ser transitório através da redução de outras despesas do orçamento, uma vez que a despesa com juros poderá ser eliminada em um momento em que a taxa de juros for reduzida. Obviamente, o problema reside na continuidade de taxas de juros elevadas por grandes períodos de tempo, que pressionam os encargos financeiros das políticas monetária e cambial em detrimento das despesas fiscais.

\section{O ÚLTIMO ANO DO MANDATO}

A fim de evitar que ações possam ser iniciadas no último ano de mandato, comprometendo os orçamentos futuros, a LRF impõe algumas restrições quanto aos restos a pagar, o aumento de despesas de pessoal e quanto às operações de crédito.

No que diz respeito aos restos a pagar, o Artigo 42 proíbe que o titular de Poder ou órgão público contraia, nos dois últimos quadrimestres do seu mandato, obrigações de despesa que não possa ser cumprida integralmente dentro do exercício ou que deixe parcelas para serem pagas no exercício seguinte sem disponibilidade de caixa para isso.

\footnotetext{
${ }^{5}$ LC 101, Art. 14.

${ }^{6}$ Esse dispositivo já foi colocado em prática quando da aprovação do novo salário mínimo, no final do ano de 2000 vigorarando a partir de abril de 2001, para o qual foi aprovada um conjunto de medidas para aumentar a arrecadação, o que incluía a quebra do sigilo bancário de possíveis sonegadores.
} 
No que diz respeito ao gasto com pessoal, a LC 101 impede aumento de despesas nos 180 dias anteriores ao final do mandato (Art. 21). As operações de crédito por antecipação de receita orçamentária (ARO) estão proibidas durante todo o último ano de mandato (Art. 38). ${ }^{7}$

No último ano de mandato, se o ente federativo exceder o limite para o montante da dívida já no primeiro quadrimestre, ficará proibido de realizar operações de crédito, exceto o refinanciamento do principal atualizado da dívida mobiliária (Art. 31). Deverá ainda promover limitação de empenho, entre outras medidas, para a recondução ao limite.

\section{O CONTROLE DA DÍVIDA PÚBLICA}

A LC 101 não estipula novos limites para o endividamento público, mas estabelece que o Presidente da República deverá encaminhar ao Senado proposta de limites para as dívidas da União, estados e municípios, conforme os Artigos 48 e 52 da Constituição Federal. O presidente deve também enviar projeto de lei ao Congresso Nacional propondo limites para o montante da dívida mobiliária federal (LC 101, Art. 30). Em agosto de 2000, foram encaminhadas ao Congresso Nacional as propostas de limites globais para o montante da dívida consolidada líquida da União, estados e municípios, da dívida mobiliária federal, assim como a metodologia para o cálculo do resultado primário fiscal dos entes federativos. Pelos projetos apresentados, os limites da dívida líquida em relação à receita corrente líquida são os seguintes: 3,5 para a União, 2 para os estados e 1,2 para os municípios, valores que, segundo a exposição de motivos do projeto, já representam a média do endividamento observado. Ressalte-se que os entes federativos que tiveram sua dívida renegociada não podem emitir títulos.

Em dezembro de 2001, foram aprovadas as Resoluções 40 e 43 do Senado Federal, que regulamentaram as normas de endividamento de estados e municípios, substituindo a Resolução 78 de 1998. Os novos limites são de 1,2 para municípios e 2 para estados, em termos de dívida líquida, abrangendo no cálculo não só a administração direta mas também os fundos, as autarquias, as fundações e as empresas estatais dependentes, com um período de ajuste de quinze anos, na proporção de 1/15 ao ano. ${ }^{8}$ Além disso, o comprometimento anual com amortizações, juros e demais encargos da dívida passam de $13 \%$ da receita líquida real, conforme a Res. 78/98, para 11,5\% da receita corrente líquida. Já o montante anual das operações de crédito, que era de $18 \%$ da receita líquida real passou para $16 \%$ da receita cor-

\footnotetext{
${ }^{7}$ Restrição já em vigor pela Resolução 78/98 (Art. 18).

${ }^{8}$ A Res. 78/98 abrangia apenas estados, municípios e suas respectivas autarquias e fundações, deixando de lado as estatais dependentes.
} 
rente líquida e as garantias passam de $25 \%$ da receita líquida real para $22 \%$ da receita corrente líquida.

Observe-se, portanto, que a LC 101 traz o arcabouço institucional geral, mas não define os limites da dívida pública, deixando o detalhamento para outros instrumentos legais. Por outro lado, ela permite alguma flexibilidade em caso de instabilidade econômica ou alterações na política monetária ou cambial. Nesse caso, o Presidente deverá encaminhar ao Congresso solicitação de revisão dos limites (LC 101, Art. $\left.30 \$ 6^{\circ}\right){ }^{9}$

A novidade da LC 101 é já explicitar a regra de que os limites da dívida serão apurados em relação à receita corrente líquida e não pela receita líquida real, conforme a Resolução 78/98. ${ }^{10}$ Além disso, as Resoluções 40 e 43 de 2001 estabelecem que a variável de controle é a dívida líquida, ou seja, a dívida consolidada, deduzidas as disponibilidades de caixa e as aplicações financeiras.

Uma inovação na LC é a proibição de operações de crédito entre entes da federação, incluindo refinanciamento ou postergação de dívida contraída anteriormente. Essa proibição é drástica, incluindo os fundos (exemplo, FGTS), autarquias (ex. INSS), fundação ou empresa estatal (Art. 35). A única flexibilidade permitida é a possibilidade de instituição financeira estatal realizar operações de crédito com ente federativo para financiar despesas de capital ou refinanciar dívidas contraídas junto à própria instituição. Este é um ponto fundamental para garantir que a responsabilidade fiscal seja a conduta normal dos níveis sub-nacionais de governo, pois dá uma sinalização aos governantes de que novos problemas em relação ao excesso de endividamento não mais serão repassados ao governo central e posteriormente socializados entre a população como um todo. ${ }^{11}$

Note-se que já a Resolução 78/98 proibia novas operações de crédito caso o ente federativo ultrapassasse os limites permitidos da dívida. A LC 101 e as Resoluções 40 e 43 modificam o procedimento para a autorização de novas dívidas: anteriormente, pela Res. 78/98, os pedidos de novas operações eram encaminhados ao Banco Central, que emitia um parecer técnico, cabendo a decisão final ao Sena-

\footnotetext{
${ }^{9}$ No caso de uma economia em "funcionamento normal”, o período de apuração do limite da dívida é o quadrimestre e o prazo para recondução ao limite são os três quadrimestres seguintes, reduzindo-se o excedente em pelo menos $25 \%$ no primeiro.

${ }^{10}$ A receita corrente líquida (RCL) inclui o somatório das receitas tributárias, de contribuições, patrimoniais, industriais, agropecuárias, de serviços, transferências correntes e outras receitas correntes menos, as transferências por determinação legal, assim como a contribuição dos servidores para o custeio de seu sistema de previdência. Ela é mais ampla do que a receita líquida real da Res. 78/98 pois esta incluía as receitas dos últimos 12 meses de apuração, deduzidas as operações de crédito, da anulação de restos a pagar, de alienação de bens, de transferencias vinculadas ou voluntárias, apesar de incluir o superávit financeiro das autarquias e fundações (exceto as previdenciárias) e as receitas do ICMS destinadas a empréstimos e financiamentos incentivados.

${ }^{11}$ Sobre o papel da LRF enquanto restrição institucional ao descontrole do endividamento público ver Baia (2000).
} 
do. Havia um mecanismo mais restritivo quanto à operacionalização de dívida nova na Res. 78/98, pois o Bacen não poderia encaminhar ao Senado nenhum pedido de autorização de operação de crédito se o ente apresentasse resultado primário negativo ou estivesse inadimplente junto a instituições do sistema financeiro. A partir das Resoluções 40 e 43, os pleitos devem ser encaminhados ao Ministério da Fazenda, que não encaminhará o pedido ao Senado em caso de inadimplência, não havendo mais a restrição quanto ao superávit primário.

Há ainda outras proibições importantes na LRF, relacionadas à dívida pública:

1) realização de empréstimos por parte das unidades da federação junto aos bancos por elas controladas; 2) captação de recursos como antecipação de receita de tributo cujo fato gerador ainda não tenha ocorrido; 3) recebimento antecipado de valores de empresa em que o Poder Público detenha a maioria do capital com direito a voto, exceto lucros e dividendos, de modo a evitar eventos do tipo em que uma empresa antecipa os royalties devidos a cada ano em um momento do tempo; 4) assunção de compromisso ou confissão de dívida com fornecedores mediante emissão de título ou aval de título de crédito; ${ }^{12} 5$ ) assunção de obrigação, sem autorização orçamentária, com fornecedores para pagamento a posteriori de bens e serviços.

Em relação às operações de crédito por antecipação de receita orçamentária (ARO), o Art. 38 da LC 101 estabelece que: 1) só poderão ocorrer a partir do décimo dia do início do exercício e deverão ser liquidadas até o dia 10 de dezembro de cada ano; 2) não poderão incluir outros encargos além da taxa de juros da operação; 3) não poderão existir enquanto uma outra operação anterior da mesma natureza não tiver sido liquidada; 4) não poderão ocorrer no último ano do mandato; 5) deverão ocorrer dentro de um processo competitivo eletrônico organizado pelo Banco Central.

O Ministério da Fazenda deverá verificar o enquadramento dos limites da dívida e divulgar a lista dos entes que estão fora deles. Se a dívida consolidada ultrapassar o limite ao final do quadrimestre, deverá ser reconduzida até o término dos três subseqüentes ${ }^{13}$ ficando o ente da Federação proibido de realizar operação de crédito interna ou externa, inclusive AROs. ${ }^{14} \mathrm{O}$ prazo poderá ser ampliado em até quatro quadrimestres se ocorrerem mudanças importantes nas políticas monetária e cambial. Se houver um período recessivo, com crescimento do PIB nacional, estadual e regional inferior a $1 \%$ do acumulado nos 12 meses anteriores, o período de três quadrimestres para o ajuste poderá também ser duplicado. ${ }^{15}$

\footnotetext{
${ }^{12}$ A LC permite, entretanto, que as empresas estatais realizem operações de crédito com seus fornecedores, o que certamente garante a elas mais flexibilidade em sua atuação.

${ }^{13}$ Note-se que aqueles entes federativos que estão acima dos limites estipulados pela Resolução 40/2001 devem realizar o ajuste em quinze anos, na proporção de 1/15 por ano, e depois entram na regra para aqueles já ajustados, com enquadramento quadrimensal.

${ }^{14}$ LC 101, Artigo 31. Apenas será possível o refinanciamento do principal atualizado da dívida mobiliária.

${ }^{15}$ No item 7, a seguir, apresentar-se-á uma discussão sobre a questão da dificuldade do ajuste em períodos de recessão.
} 


\section{LIMITES DE GASTOS COM PESSOAL}

No que diz respeito aos limites com gastos de pessoal, instrumento já previsto no Artigo 169 da Constituição Federal, a LRF aprofunda a Lei Camata, que já determinava os limites com pessoal e previa prazo para readequação dos entes federativos que estivessem a cima do limite. As despesas com pessoal incluem aquelas com ativos, inativos e pensionistas. Os limites definidos pela $\mathrm{LC} \mathrm{n}^{\circ} 101$, por nível de governo, são, assim como a dívida, determinados em relação à receita corrente líquida (RCL). Os gastos com pessoal, por nível de governo, podem ser observados na tabela 1 , a seguir.

Tabela 1: Gastos com Pessoal por Nível de Governo (\% da RCL)

\begin{tabular}{cc}
\hline União & $50 \%$ \\
Estados & $60 \%$ \\
Municípios & $60 \%$ \\
\hline
\end{tabular}

Fonte: LC 101, 4/5/2000, Art. 19.

Para a apuração das despesas de pessoal, a LC determina que seja somada a despesa realizada no mês de referência com as dos onze anteriores, segundo o regime de competência, e nesses limites não devem ser incluídos gastos com demissão de servidores, incentivos à demissão voluntária, gastos com convocações extraordinárias do congresso, despesas com inativos custeadas por fontes específicas. Também no que diz respeito às despesas com pessoal, os limites entre os poderes variam de acordo com o nível de governo, conforme tabela 2 .

A verificação do enquadramento dos limites da despesa de pessoal tem dois momentos. O primeiro é o período de transição, conforme o artigo 70 da LRF: se o órgão ou poder estiver acima dos limites no exercício anterior à LC 101, ou seja, no exercício de 1999, deverá se enquadrar em até dois exercícios, ou seja até 2002, eliminando-se o excesso em pelo menos 50\% no primeiro ano. Num segundo momento, após o período de transição, a verificação deverá ser feita ao final de cada quadrimestre ${ }^{16}$ e caso a despesa de pessoal exceda os limites, deverá haver redução nos dois quadrimestres seguintes, eliminando-se o excesso em pelo menos um terço no primeiro. ${ }^{17}$

No que tange ao gasto com pessoal, portanto, o aspecto mais importante na lei é a grande importância atribuída às metas quantitativas, com a determinação

\footnotetext{
${ }^{16}$ LC 101, Art. 22.

${ }^{17}$ Por outro lado, a LRF pretende prevenir contra aumentos de gastos com pessoal para os entes que estiverem abaixo do limite. Neste caso, segundo o Artigo 71, até o término do terceiro exercício seguinte à LC 101, logo 2003, as despesas com pessoal não podem ultrapassar a despesa verificada no ano anterior acrescida de até $10 \%$ da receita corrente líquida.
} 
dos percentuais máximos possíveis mesmo entre os diversos poderes, ampliando a determinação anterior da Lei Camata. Essa maior rigidez no nível dos gastos é suavizada pelo prazo de ajuste: no caso de haver excesso com pessoal no exercício de 1999, o ajuste poderá ser realizado em até dois anos. Uma vez enquadrados, se houver um novo desajuste, o período de readequação vai até os dois quadrimestres seguintes. No caso de recessão econômica, definido na lei como crescimento do PIB inferior a $1 \%$ em pelo menos um período de quatro trimestres, o período de ajuste dobra, portanto, se torna quatro quadrimestres. ${ }^{18}$

Em relação aos limites por poderes, que na elaboração da lei foi uma demanda dos governos estaduais, note-se ainda que há um custo fixo diferenciado em todos eles e a definição de percentuais fixados em relação à receita pode acabar gerando certas distorções. Isto porque o percentual determinado pela lei pode não corresponder às necessidades de cada poder em cada região, pois a definição foi efetuada através de uma média de gastos atualmente verificados em nível nacional. Cabe destacar ainda que o projeto de lei enviado inicialmente previa que a LDO poderia estabelecer limites diferentes e apenas caso a LDO não estipulasse nenhum outro limite, valeria o definido pela LFR.

A imposição de limites de comprometimento com pessoal partiu do princípio de que o setor público brasileiro apresenta uma tendência a possuir excesso de pessoal. A fixação dos limites pode acabar impondo certas restrições de atuação. Parece razoável supor que em determinadas situações, nas quais o investimento na máquina pública deva ser elevado, o comprometimento das receitas com despesas de pessoal seja reduzido. Entretanto, em outras situações, nas quais se observa que o setor público apresenta uma infra-estrutura adequada, o comprometimento com pessoal pode ser mais elevado. Também não podemos esquecer que o setor público, por sua própria natureza, opera em setores normalmente mais trabalho intensivo, assim como desempenha atividades de organização institucional da sociedade, como planejamento, regulação e repressão de condutas indevidas. E tudo isto é feito com processos produtivos e trabalho intensivos, de modo que a imposição de limites pode distorcer a alocação mais adequada de escolha do processo ou mesmo induzir a mecanismos para ultrapassar os limites legais, como seria um estímulo a terceirização. ${ }^{19}$

Uma outra questão que diz respeito à questão de pessoal é que não só o volume dos serviços oferecidos poderá estar abaixo do requerido pela população, mas também poderá haver deficiências na qualidade dos serviços oferecidos. Sabe-se que no setor de serviços, em que o papel dos incentivos salariais e do investimento em capital humanos são indispensáveis face à evolução tecnológica, os limites sobre a des-

\footnotetext{
${ }^{18}$ Ver item 7 sobre ajuste de despesas de pessoal e ciclo econômico.

${ }^{19}$ O Art. 18 da LRF diz que os valores dos contratos de terceirização de mão-de-obra na substituição de servidores serão contabilizados como "outras despesas de pessoal”, fora do cálculo do teto de $60 \%$
} 
Tabela 2: Limites para Gastos com Pessoal, em percentagem da Receita Líquida, por Poder e Esfera de Governo (\%)

\begin{tabular}{lccc}
\hline \multicolumn{1}{c}{ Poder } & União & Estados & Municípios \\
\hline Legislativo + TC & 2,5 & $3+0,4$ (caso tenha TCM) & 6 \\
Judiciário & 6 & 6 & - \\
Executivo & 40,9 & $49-0,4$ (caso tenha TCM) & 54 \\
Ministério Público & 0,6 & 2 & - \\
\hline \multicolumn{1}{c}{ Total } & 50 & 60 & 60 \\
\hline
\end{tabular}

Fonte: LC 101, 4/5/2000, Art. 20.

Notas: TC Tribunal de Contas; TCM Tribunal de Contas dos Municípios.

pesa de pessoal, especialmente em períodos de redução do crescimento econômico, poderá comprometer sua qualidade na medida em que os profissionais poderão sair do setor público rumo a oportunidades mais rentáveis no setor privado.

\section{A TRANSPARÊNCIA E PARTICIPAÇÃO POPULAR}

Estas duas qualidades da gestão pública se materializam na LC 101 através da exigência de realização de audiências públicas na elaboração das peças orçamentárias e de ampla divulgação de relatórios da execução fiscal. ${ }^{20}$ Isto sem dúvida é um grande avanço, principalmente se pensarmos que a consulta à população torna-se cada vez mais fácil através da tecnologia da informação.

Em relação aos serviços públicos, o que se observa é uma certa insatisfação por parte da população brasileira, seja em decorrência da escassez de serviços, seja por sua baixa qualidade. Há um senso-comum no Brasil de que se paga muito pelo que se recebe, o que sem dúvida é uma generalização do problema pois há uma ampla gama de possibilidades de combinações possíveis de serviços e qualidade, além da carga tributária ser também bastante diversa entre os indivíduos e classes de renda. Contudo, essa percepção do problema, mesmo que parcial, sugere que muito provavelmente os cidadãos-contribuintes gostariam de ser consultados sobre os serviços que gostariam de ter à sua disposição e como financiá-los, em outras palavras, o tamanho e funcionalidade do Estado.

Um instrumento adicional para a democratização do novo arranjo legal é a criação do Conselho de Gestão Fiscal, previsto no Artigo 67 da LRF. Este conselho deverá avaliar a política e operacionalização da gestão fiscal responsável, tendo como participantes os representantes de todos os poderes e níveis de governo, do Ministério Público e de entidades representativas da sociedade. Entre suas atribuições,

${ }^{20}$ Art. 48 da LC 101. 
ele deverá padronizar e orientar a execução da LRF, assim como disseminar práticas fiscais adequadas.

A Lei de Responsabilidade Fiscal certamente avança na democratização da escolha do uso dos recursos públicos ao obrigar as autoridades a realizarem audiências públicas e divulgarem as informações pela Internet e demais meios de comunicação, assim como através da disseminação de experiências e modelos de gestão fiscal bem sucedidas. Entretanto, é longo o caminho do aprendizado das novas práticas democráticas e da boa gestão fiscal.

\section{AS PENALIDADES}

As penalidades são gradativas, começando pela suspensão das transferências voluntárias em caso do ente federativo não explorar suas possibilidades tributárias ou promover o ajuste com pessoal, penalidades estas que recaem sobre o ente federativo em si e já estão incluídas na LC 101 (Artigos 11 e 23). ${ }^{21}$

Do ponto de vista da responsabilidade pessoal dos gestores, as penas, conforme a Lei $n^{\circ} 10.028 / 2000$, são apresentadas a seguir.

I. Multa de 30\% dos vencimentos anuais do responsável, no caso de: 1) deixar de enviar relatório de gestão fiscal ao final de cada quadrimestre; 2) não incluir metas fiscais na LDO; 3) deixar de determinar limitação de empenho e movimentação financeira prevista na LC 101; 4) deixar de promover o ajuste de pessoal.

II. Detenção de 3 meses a um ano: no caso de prestação de garantia em operação de crédito sem contragarantia em valor igual ou superior.

III. Detenção de 6 meses a dois anos: 1) inscrição em restos a pagar de despesas não empenhadas previamente ou que excedam limite legal; 2) deixar de promover o cancelamento dos restos a pagar de valor superior ao permitido por lei.

IV. Reclusão de um a quatro anos: para realização de operação de crédito sem autorização legislativa ou sem obedecer aos limites legais.

V. Reclusão de um a quatro anos: para assunção de obrigações nos últimos 8 meses de mandato cuja despesa não possa ser paga no mesmo exercício financeiro ou que não tenha disponibilidade de caixa para seu pagamento no exercício seguinte.

VI) Reclusão de um a quatro anos:1) ordenar despesa não autorizada por lei;

2) ordenar aumento da despesa com pessoal nos 6 meses anteriores ao final do mandato; 3) ordenar a colocação no mercado financeiro de títulos da dívida pública sem que tenham sido criados por lei ou registrados no sistema centralizado de liquidação e custódia.

Pelo conjunto das penalidades, verifica-se que as piores são aquelas relativas ao não cumprimento das regras quanto ao último ano de mandato e quanto às ope-

\footnotetext{
${ }^{21}$ A proibição de transferências voluntárias exclui aquelas com saúde, educação e assistência social.
} 
rações de dívida pública, o que sugere que o aperto legal é uma conseqüência a algumas administrações públicas problemáticas nesses aspectos, ou seja, seriam as piores "falhas de governo" no passado recente do setor público brasileiro. ${ }^{22}$ Além disso, dada a complexidade de regras e procedimentos quanto às operações de crédito, pode-se deduzir que o objetivo maior do novo arranjo legal é, de fato, o controle da dívida pública.

Há que se observar, também, que no intuito de se adequar às novas exigências legais, evitando assim punições severas, muitas vezes ocorre justamente o inverso do pretendido pela regulação, que é a gestão responsável. Exemplo disso foi o cancelamento dos empenhos de diversas prefeituras no final do ano de 2000, último ano do mandato das prefeituras, mesmo quando os serviços para elas já tinham sido prestados e as mercadorias já tinham sido entregues, logo, com a expectativa e direito certos dos diversos credores. Essa atitude, longe de melhorar a percepção de risco da sociedade com o setor público, só a piorou, pois novamente os credores devem fazer uma renegociação amigável ou judicial de seus créditos.

\section{AVALIAÇÃO MACROECONÔMICA DA LEI DE RESPONSABILIDADE FISCAL}

A Lei de Responsabilidade Fiscal tem como um de seus objetivos criar as condições para o equilíbrio orçamentário. A necessidade de se fazer uma adequação do volume de despesas ao volume de receitas, indiscutivelmente, é fundamental para qualquer agente econômico. Nesse sentido ela procura dar parâmetros que auxiliem o alcance do equilíbrio orçamentário. Em função das características dos orçamentos públicos, a LRF identifica dois parâmetros estratégicos de controle: limites de comprometimento com as despesas de pessoal e limites de endividamento. Adicionalmente, através da Lei 10.028, aprovada também no ano de 2000 (Lei dos Crimes Fiscais) introduz-se uma série de punições caso os administradores públicos realizem despesas sem a cobertura orçamentária necessária.

Dentro desse sentido mais amplo, a LRF é fundamental pois ressalta a noção básica de que a atuação adequada do setor público no desempenho de suas funções passa pela obtenção de finanças adequadamente administradas. É claro que a obtenção de um setor público eficiente, atuando de maneira adequada na solução dos diversos problemas de uma sociedade, é uma tarefa complexa que engloba inúmeros outros aspectos e não meramente o equilíbrio orçamentário. A ação eficiente do setor público passa necessariamente por uma aplicação adequada dos recursos, bem como por uma distribuição adequada dos bens públicos e meritórios

\footnotetext{
22 Não só problemáticas, mas também grandes do ponto de vista dos entes federativos, a ponto de terem causado desequilíbrios relevantes no setor público no passado recente. Exemplos: Município de São Paulo e Estado de São Paulo.
} 
para os segmentos mais carentes da população. Por outro lado exige uma ação coordenada no sentido de que a economia possa apresentar um crescimento econômico sustentável ao longo do tempo.

Essas considerações não devem ser entendidas como críticas à Lei de Responsabilidade Fiscal, mas sim como uma constatação de que o equilíbrio orçamentário por si só não implica a adequada aplicação dos recursos públicos e conseqüentemente uma ação eficiente do Estado.

Nessa direção, a discussão do equilíbrio orçamentário não esgota o debate sobre a qualidade da atuação do setor público. Em primeiro lugar é fundamental que a noção de equilíbrio orçamentário seja precedida por uma ampla discussão do papel do setor público no Brasil, a fim de que sejam definidas suas funções, suas estruturas, pois o volume de recursos que o setor privado deverá transferir para financiar as atividades do setor público dependerá dessas definições. Nesse sentido, é essencial que essa discussão seja efetuada de maneira clara e precisa, pois o equilíbrio orçamentário pode ser obtido considerando qualquer volume de recursos, evidentemente, dependendo do volume de recursos, teremos uma determinada oferta de serviços públicos.

Essa questão é extremamente importante porque o que se assiste hoje no Brasil são duas forças opostas que acabam pressionando os administradores públicos. De um lado, em função dos inúmeros problemas sociais existentes em nosso país, o setor público vê-se obrigado a realizar uma série de gastos a fim de solucionar tais problemas. Por outro lado, vê-se também obrigado a adequar o volume de gastos à disponibilidade de receitas para atingir o equilíbrio orçamentário.

Ainda neste ponto, é importante acentuarmos que, dada a realidade econômica e social de nosso país, e considerando toda a ampla gama de ações que a população espera do setor público, torna-se bastante difícil evitar que não sejam gerados déficits orçamentários. As pressões orçamentárias são ainda mais acentuadas quando entramos na discussão da eficiência dos gastos públicos.

A noção de eficiência dos gastos públicos pode ser analisada sob várias óticas. Em primeiro lugar, argumenta-se que o setor público não utiliza os recursos de maneira eficiente do ponto de vista da eficiência produtiva. O processo de privatização desenvolvido em vários países partiu da noção de que as empresas públicas eram menos eficientes do ponto de vista produtivo do que as empresas privadas.

Uma outra dimensão que devemos considerar pode ser melhor entendida quando dividimos os gastos públicos considerando duas características: gastos corretivos e preventivos. Os gastos corretivos representam gastos que o setor público é obrigado a executar a fim de atenuar certos problemas sociais, sem, contudo, conseguir atacar suas verdadeiras causas. Os gastos que poderiam ser enquadrados nesta natureza são os gastos tipicamente associados à área da saúde corretiva, boa parte deles associada às áreas de assistência social, segurança, etc., cuja característica principal é a de não atacar as reais causas do problemas que os originam, ainda que adquiram um caráter de essencialidade pela sua característica de solucionar ou atenuar tempo- 
rariamente os problemas. Admitamos, por exemplo, que numa determinada situação de insalubridade ambiental as pessoas adquiram certas doenças. Evidentemente o setor público será pressionado pela sociedade para que construa hospitais, contrate médicos, forneça medicamentos etc., visando atender essa população. Se, entretanto, não forem adotadas ações que eliminem o foco causador das doenças, ou seja, se as causas primárias não forem atacadas, o gasto corretivo com a saúde vai acabar se perpetuando e pressionando sistematicamente os orçamentos públicos. O exemplo dado, na área da saúde, pode ser estendido para outras áreas, como segurança, assistência social, etc. Podemos ilustrar uma situação semelhante na área da segurança. Os inúmeros problemas sociais existentes numa sociedade como a brasileira podem elevar o número de delitos, exigindo, conseqüentemente, que o setor público desenvolva ações na área de segurança (contratação de policiais, compra de armamentos, etc.). Esta situação exigirá novamente a adoção de mecanismos de segurança (contratação de guardas, armamentos, etc.) que também passam a comprometer o orçamento público, sem atacar as causas originais dos problemas. Em larga medida os gastos sociais adquirem uma característica assistencialista, de natureza corretiva, sem, contudo, atacar as causas primárias dos problemas.

Em suma, a fim de contornar certos problemas sociais, o setor público vai desenvolvendo ações que acabam cristalizando nos orçamentos públicos gastos de natureza corretiva, sem aliviar ou atenuar as causas primárias dos problemas, dando aos orçamentos um grau de inflexibilidade bastante elevado. Normalmente, quando se discute da necessidade de redução das despesas públicas, tais aspectos não são ressaltados com a devida importância, pois embora sejam essenciais, tais ações não atacam as verdadeiras causas dos problemas.

Por outro lado, os gastos preventivos seriam aqueles que buscam atacar as causas primárias dos problemas. Nesta categoria os gastos mais importantes são, indiscutivelmente, os ligados à área da educação, pela sua característica de fornecer à população instrumentos adequados para que ela possa engajar-se em atividades econômicas com maior geração de renda. Naturalmente, podemos adicionar também os gastos relacionados com a saúde preventiva, além de outros gastos sociais que evitem o surgimento de problemas sociais futuros.

O grande problema na alocação dos recursos públicos é que os gastos corretivos, pela sua urgência, acabam pressionando de maneira significativa os orçamentos, podendo comprometer os gastos preventivos. No caso do Brasil, em função da péssima distribuição de renda, a pressão por gastos corretivos é enorme..$^{23}$ Isto porque essa desigualdade econômica gera inúmeros problemas sociais que exigem ações do setor público tanto de natureza preventiva como corretiva. De um lado, o setor público vê-se obrigado a desenvolver as ações de natureza corretiva. De ou-

\footnotetext{
${ }^{23}$ Para que se tenha uma idéia do perfil da distribuição de renda no Brasil, de acordo com os dados da Fundação Instituto Brasileiro de Geografia e Estatística (FIBGE), em 1999, 50,07\% da população economicamente ativa ganhava até 2 (dois) salários mínimos, recebendo $14,75 \%$ da renda gerada.
} 
tro, sabe da importância dos gastos preventivos. Esse conjunto de pressões acaba tradicionalmente gerando outras muito fortes para que os gastos públicos acabem superando os recursos disponíveis, gerando, conseqüentemente, o déficit público.

Assim, dentro destas noções, a LRF acentua a exigência de equilíbrio orçamentário, num setor público atuando num país com inúmeros problemas sociais e com uma sociedade que exige soluções do governo. Por outro lado, fruto dessas tradicionais pressões e dos próprios problemas existentes, os orçamentos públicos acabaram por ser dominados por gastos corretivos em detrimento dos preventivos.

Um outro aspecto bastante discutível na LRF refere-se à vinculação da oferta de serviços públicos às oscilações cíclicas da economia. Tal vinculação deriva fundamentalmente dos limites dados às despesas de pessoal e endividamento. Como salientado acima, as despesas de pessoal não podem exceder $60 \%$ da receita corrente líquida no caso dos estados e municípios.

Vamos admitir que um determinado estado esteja cumprindo exatamente os limites impostos pela LRF. Vamos supor que em virtude de algum fator alheio à política econômica do Estado, ocorra um declínio da atividade econômica que certamente acabará refletindo numa diminuição de sua receita corrente líquida. Nesse sentido, as despesas de pessoal deverão ser reduzidas a fim de que se restabeleça o limite imposto pela lei.

Essa recondução aos limites é certamente bastante difícil caso a economia esteja num período recessivo. Isto porque, se o nível de atividades está em queda, provavelmente estará havendo um aumento das problemas sociais, e justamente nessa situação o setor público é obrigado a cortar despesas. Por outro lado, não podemos esquecer da distinta natureza dos bens e serviços públicos daqueles produzidos pelo setor privado. Caso uma empresa privada tenha problemas de receitas, o corte das despesas significará uma redução da produção do seu produto. Ainda que isto possa trazer uma série de dificuldades, certamente serão menores quando levar em conta que a redução das despesas públicas acarretará a diminuição dos serviços de saúde, educação e segurança, etc.

Em outras palavras, deixar que a oferta de serviços públicos fique atrelada aos naturais movimentos cíclicos da atividade econômica não parece ser uma proposta adequada. Aqui se percebe claramente a prioridade que o equilíbrio orçamentário ganha em relação a quaisquer outros objetivos da atividade pública. A única salvaguarda prevista pela lei está colocada no seu Artigo 66, que afirma que Os prazos estabelecidos nos arts. 23, 31 e 70 (prazos para o restabelecimento dos limites de pessoal e divida) serão duplicados no caso de crescimento real baixo (inferior a $1 \%$ ao ano) ou negativo do Produto Interno Bruto (PIB) nacional, regional ou estadual por perído igual ou superior a quatro trimestres. Como se nota, apenas se aumenta o período de adequação à nova situação econômica.

Poder-se-ia argumentar que se o produto crescer a taxas inferiores durante quatro trimestres, isto indicaria efetivamente uma redução da taxa de crescimento do produto de caráter mais estrutural. Entretanto, não podemos esquecer que os 
ciclos econômicos de curto prazo podem levar mais do que quatro trimestres. Em segundo lugar, se durante dois trimestres se observar um declínio das taxas de crescimento do produto, os administradores públicos já terão que começar a tomar medidas redutoras destas despesas, pois, caso esperem efetivamente os quatro trimestres, terão maiores dificuldades de se ajustarem posteriormente. Portanto, os administradores públicos vão ter que transformar a oferta de serviços públicos atrelada aos tradicionais movimentos cíclicos da economia.

Um último aspecto que devemos considerar refere-se à questão entre a responsabilidade fiscal e a responsabilidade social. De modo geral ela tem sido conduzida como se fossem aspectos antagônicos da gestão pública, ou seja, aqueles que defendem a responsabilidade fiscal não estariam se preocupando com a responsabilidade social e vice versa. Na realidade, como ressaltado por Montoro, ${ }^{24}$ é impossível haver responsabilidade social sem a contrapartida da responsabilidade fiscal pois o setor público não poderá conduzir de maneira consistente ao longo do tempo um programa de ação contra certos problemas sociais sem contar com recursos para o desenvolvimento desses programas. Por outro lado, também não podemos deixar de registrar que, se não houver uma responsabilidade social ao longo do tempo, estaremos comprometendo a responsabilidade fiscal. Isto porque, caso os orçamentos públicos estejam equilibrados, mas os problemas sociais não estejam sendo adequadamente solucionados, ao longo do tempo as pressões sobre os gastos públicos serão de tal ordem que certamente não se poderá manter o equilíbrio orçamentário.

\section{CONSIDERAÇÕES FINAIS}

Em um sentido mais amplo, o novo arcabouço institucional para o setor público brasileiro destaca o princípio do equilíbrio fiscal e da responsabilização pela má condução dos recursos públicos. A questão sobre as funções, o tamanho do Estado e o nível de gastos desejados pela sociedade permanece, contudo, para discussões políticas, acadêmicas e técnicas.

Dado o novo quadro institucional, pode-se esperar um maior controle sobre o setor público a partir de uma maior divulgação das informações, propiciada pela LRF, e que os desvios por parte dos políticos ou burocratas serão mais facilmente apontados e punidos do que anteriormente, de modo que a sociedade tenha uma forma mais eficaz de lidar com o mau gestor público do que a mera indignação. Nesse sentido, o novo conjunto de regras ajudará a sanar uma "falha de governo", qual seja a percepção por parte dos administradores públicos de que suas ações não são restringidas por nenhuma restrição orçamentária e que sempre é possível

\footnotetext{
${ }^{24}$ Ver o artigo de André Franco Montoro Filho "Responsabilidade Social Começa com Responsabilidade Fiscal”, Resenha Econômica, Cepam, junho/2001.
} 
repassar os custos de uma administração perdulária para seus sucessores ou outros níveis de governo, ou seja, para a sociedade como um todo.

De um ponto de vista mais específico, como qualquer outro conjunto de novas regras, há pontos positivos e negativos.

A LC 101 implica um maior detalhamento e transparência do processo de planejamento público, criando um ambiente propício ao estabelecimento de metas fiscais quantitativas, acompanhamento e controle da ação pública através dos indicadores e relatórios. Ela cria também um ambiente favorável à exploração da base tributária própria dos entes federativos e a necessidade de ajuste em caso de aumento permanente de despesas. A LRF é portanto um instrumento para uma gestão fiscal equilibrada e aberta, com objetivos, metas e indicadores explicitados claramente, em que a sociedade é chamada a participar na tomada de decisões e no próprio controle da ação estatal, seja através de audiências públicas ou da disseminação de informações por meio eletrônico.

No caso de crescimento real baixo (inferior a 1\%) ou negativo do Produto Interno Bruto os prazos para o ajuste das contas de despesa com pessoal e dívida são duplicados. Apesar dessa ampliação de prazos, a LRF apresenta um aspecto curioso na forma de atuação do setor público. Isto porque dentro da tradição keynesiana admite-se que o setor público tenha importante papel para atenuar os ciclos econômicos. Nesta perspectiva, os gastos públicos deveriam ser ampliados nos períodos recessivos e contraídos nos períodos de expansão. Por outro lado, o cumprimento da LRF exige uma ação oposta. Em períodos recessivos os gastos públicos devem ser reduzidos e ampliados nos períodos de expansão.

Em relação ao último ano de mandato, o nível de tolerância é mínimo, de modo que o impacto negativo do ciclo político deve ser bastante suavizado. Considerando-se a questão do ciclo econômico discutida anteriormente, resta esperar que no último ano de mandato, especialmente dos governos federal e estadual, grandes agentes públicos que podem afetar decisivamente a economia, não ocorra uma recessão profunda, pois nesse caso, a LRF vai representar um obstáculo substancial à retomada da economia.

Em relação ao endividamento público, conforme observado anteriormente, não há na própria LC 101 a definição de limites de pagamento e de tamanho de dívida, mas isto é remetido a um novo arranjo legal, seguindo o processo pertinente. A inovação é a proibição de operações de crédito entre os entes federativos, de modo que os níveis inferiores de governo deverão estimar as reais possibilidades de pagamentos dentro de seu âmbito de atuação e não mais esperar pela possibilidade de repassar para outros níveis de governo o ônus de uma política fiscal mal planejada. Obviamente, as restrições ao endividamento estão sujeitas à capacidade dos entes federativos em empreenderem uma "contabilidade criativa" capaz de escapar às regras.

No contexto da dívida e retomando a questão da ausência de uma discussão sobre o tamanho e funcionalidade do Estado brasileiro, os novos níveis possíveis de endividamento de estados e municípios que foram aprovadas no Senado, em termos de 
dívida líquida, ainda que mais brandas do que a Resolução 78/98, se baseiam em tendências de endividamento passado dos governos para um determinado estoque desejável de dívida, sem vislumbrar que esses níveis dependem também do que se espera da atuação estatal como um todo no futuro, ou seja, tamanho e funções do Estado.

Um aspecto adicionalmente negativo do novo arcabouço institucional é a definição de limites rígidos, em percentual da receita corrente líquida, para a despesa de pessoal. Poder-se-ia pensar na adoção de metas de despesa de pessoal, com uma margem de variação, do mesmo modo do que no regime de metas de inflação.

\section{REFERÊNCIAS BIBLIOGRÁFICAS}

BAIA, P. F. “Era mesmo necessária uma Lei de Responsabilidade Fiscal?”. Boletim de Conjuntura, Depto. Economia FEA PUCSP, nº 49, p. 3, nov/2000.

BNDES. "Responsabilidade fiscal”. www.federativo.bndes.gov.br. BRASIL. Lei Complementar n 101, de 04 de maio de 2000. BRASIL. Lei n ${ }^{\circ} 10.028$, de 19 de outubro de 2000.

GIAMBIAGI, F. \& ALÉM, A.C. Finanças públicas: teoria e prática no Brasil. Rio de janeiro, Ed. Campus, 1999.

KHAIR, A. A. Gestão fiscal responsável; Simples Municipal: Guia de Orientação para as prefeituras. LUQUE, A. C. \& SILVA, V. M. "Planejamento, ajuste fiscal e a Lei de Responsabilidade Fiscal". Informações FIPE, SP, nº 249, p. 13-15, jun. 2001.

McKENZIE, R. B. \& TULLOCK, G. Modern political economy: an introduction to economics. McGrawHill Book Company, 1978.

MONTORO Filho, A. F. "Responsabilidade Social começa com Responsabilidade Fiscal”. Resenha Econômica, São Paulo, Cepam, junho/2001.

MUSGRAVE, R. \& MUSGRAVE, P. Finanças públicas, teoria e prática. Rio de Janeiro, Ed. Campus, 1980.

ROCHA. V. (coord). Aspectos relevantes da Lei de Responsabilidade Fiscal. São Paulo, Dialética, 2001. STIGLITZ, J. Economics of the public sector. 2a ed., Londres, Norton \& Company, 1988. 